\title{
EXPECTATIVAS DO ESTÁGIO HOSPITALAR PARA ESTUDANTES DE ENFERMAGEM
}

\author{
EXPECTATIONS ABOUT HOSPITAL INTERNSHIP FOR NURSING STUDENTS
}

\section{Josemir Almeida Lima ${ }^{a}$, Allana Bandeira Carrilho ${ }^{b}$, Linda Djeyme Santosc Uirassú Tupinambá Silva de Lima ${ }^{\mathrm{d}}$}

ajosemir_almeida@hotmail.com, ballanynha@hotmail.com, clinda-djeyme@hotmail.com, duirassulima@yahoo.com.br Centro Universitário Cesmac - Maceió (AL), Brasil

Data de recebimento do artigo: 13/05/2015

Data de aceite do artigo: 06/10/2015

\section{RESUMO}

O primeiro estágio dos graduandos de enfermagem, no âmbito hospitalar, é um momento de muitos questionamentos, dúvidas e expectativas, apesar de terem conhecimentos teóricos e práticos suficientes para atuar junto aos pacientes. Conhecer as expectativas desses alunos pode auxiliá-los a vivenciar essa etapa de forma mais tranquila. Portanto, o objetivo deste estudo foi conhecer as expectativas dos alunos de uma disciplina do curso de enfermagem em relação ao seu primeiro estágio hospitalar. Trata-se de um estudo transversal, descritivo, exploratório, com delineamento quantitativo. $\mathrm{O}$ instrumento de coleta de dados foi um questionário semiestruturado com questóes fechadas, e participaram do estudo 44 alunos. A análise dos resultados evidenciou que a maioria dos estudantes concentra-se na faixa etária de 20 a 29 anos (65,90\%); é do sexo feminino (88,64\%); sem experiência na área de enfermagem (75\%); com expectativas de adquirir confiança $(65,91 \%)$; ansiosos $(61,36 \%)$; inseguros $(45,45 \%)$. O percentual de graduandos de enfermagem ansiosos e inseguros em relação ao primeiro estágio é alto, o que pode ter reflexos negativos no desempenho desses alunos, havendo a necessidade de intervençóes por parte dos docentes para minimizar esses problemas.

Palavras-chave: Expectativas; estágio clínico; enfermagem.

\section{ABSTRACT}

The first internship of nursing students in the hospital environment is a time of many questions, doubts, and expectations, even though they have enough theoretical and practical knowledge to work with patients. To know the expectations of these students can help them experience this step more smoothly. Therefore, the aim of this study was to know the expectations of students of a nursing program discipline regarding their first hospital internship. This is a cross-sectional, descriptive, exploratory study with quantitative design. The data collection instrument was a semi-structured questionnaire with closed questions. The study included 44 students. The analysis of the results showed that most students were in the 20-29 age group (65.90\%); females (88.64\%); with no experience in nursing (75\%); with expectations to build confidence (65.91\%); anxious (61.36\%); insecure (45.45\%). The percentage of nursing students anxious and insecure regarding their first internship is high, which may have negative effects on their performance, there being the need of interventions by the teaching staff to minimize these problems.

Keywords: Expectations; clinical internship; nursing. 


\section{Introdução}

A enfermagem é uma ciência humana, de pessoas e de experiências, voltada ao cuidado dos seres humanos, cujo campo de conhecimento, fundamentaçóes e práticas abrange desde o estado de saúde até os estados de doença, e é mediado por transaçóes pessoais, profissionais, científicas, estéticas, éticas e políticas ${ }^{1}$.

$O$ cuidado de enfermagem requer uma concepção ética que contemple a vida como um bem valioso em si, começando pela valorização da própria vida para respeitar a do outro em sua complexidade, suas escolhas, inclusive a escolha da enfermagem como profissão ${ }^{2}$.

Estagiar, desenvolver ensino clínico, praticar, é o momento de junção da teoria com a prática, ou seja, possibilita aplicar conceitos abstratos em situaçóes concretas. A prática da enfermagem pressupóe o cuidar, o supervisionar, e sob essa ótica vislumbra-se a comunicação, tendo como fator orientador a dignidade humana, o homem como ser único, e é traduzida em crescimento pessoal, com vistas ao outro ${ }^{3}$.

O primeiro estágio curricular obrigatório, que introduz o aluno na prática, propicia ao graduando experimentar sentimentos ambivalentes: por um lado, ele iniciará o estágio e sentir-se-á, pela primeira vez, inserido na profissão; por outro, ele experimentará a angústia relatada por colegas que já fizeram a disciplina ${ }^{4}$.

O estudante, durante sua formação, almeja a chegada do estágio, a hora em que realmente vai viver a "Enfermagem". Isso o excita, o encanta, mas, ao mesmo tempo - quando ele se depara com algo novo, como procedimentos, técnicas, o lidar com o outro -,o assusta ${ }^{5}$.

A maioria dos alunos, nessa etapa do curso, é ainda iniciante, inexperiente, imatura, com pouca ou nenhuma convivência com a dor, o sofrimento e a morte, que podem ser vivenciados durante a prática do estágio. A entrada repentina dos alunos numa situação desconhecida, como o estágio, é um fator desencadeante de tensóes e ansiedades, sentimentos que podem interferir negativamente no aprendizado ${ }^{6}$.

Apesar de os alunos possuírem conhecimentos teóricos e práticos suficientes para atuar junto ao paciente, nota-se que nesse momento eles se deparam com sentimentos conflituosos. Encontram-se ansiosos, inseguros, com medo de causar algum dano ao paciente, porém eufóricos com o primeiro estágio 5 . Esse passa a ser, portanto, um marco importante na sua vida enquanto aluno de um curso da área de saúde, pois representa, além de um grande desafio, uma etapa de muitos questionamentos, dúvidas e expectativas.

A disciplina Práticas Integrativas em Saúde II (PIS II) é ofertada no quinto período do curso de graduação em enfermagem do Centro Universitário Cesmac, e é através dela que os alunos vivenciam sua primeira inserção no ambiente hospitalar e, consequentemente, terão que colocar em prática seus conhecimentos técnico-científicos aprendidos nas disciplinas de Semiologia Aplicada à Enfermagem I e II, mas agora em um cenário real, com um paciente de verdade, e não mais com um manequim do laboratório de habilidades do curso de enfermagem.

Desse modo, ao cursar a citada disciplina, os alunos vivenciam os desafios e o impacto do primeiro estágio, e esse fato deu origem ao seguinte questionamento: quais as expectativas dos alunos em relação ao seu primeiro estágio no ambiente hospitalar? E a partir dele surgiram outras indagaçôes: quais os principais sentimentos experimentados pelos alunos antes de iniciar as primeiras aulas no ambiente hospitalar? Quais as suas principais dificuldades? Obter as respostas a essas perguntas, consequentemente, motivou a realização da presente investigação.

No estado de Alagoas existem mais de 10 cursos de graduação em enfermagem, e até o momento não foi identificado nenhum estudo que abordasse a temática em foco. Assim, as informaçōes advindas do presente estudo podem contribuir para o conhecimento acerca dos sentimentos, dificuldades e expectativas dos alunos em relação ao primeiro estágio. Além disso, poderâo ainda ser usadas pelos professores da disciplina Práticas Integrativas em Saúde II no planejamento e desenvolvimento de açóes e estratégias que ajudarão os seus alunos a vivenciar essa etapa da vida acadêmica de forma mais tranquila e mais proveitosa em termos de aprendizagem.

Dessa maneira, este estudo teve como objetivo conhecer as expectativas dos alunos de uma disciplina do curso de enfermagem em relação ao seu primeiro estágio hospitalar. Enunciou-se como hipótese que 90\% dos alunos que realizam o primeiro estágio não se sentem seguros na realização dos procedimentos básicos de enfermagem, e a expectativa é que ao término do estágio tenham maior segurança, domínio das técnicas e habilidades ao prestar cuidados aos pacientes.

\section{Metodologia}

Trata-se de um estudo transversal, descritivo, exploratório, com delineamento quantitativo. Foram entrevistados 44 alunos do curso de graduação em enfermagem do Centro Universitário Cesmac, situado em Maceió (AL), que estavam devidamente matriculados e presentes no primeiro dia letivo da disciplina Práticas Integrativas em Saúde II no primeiro semestre de 2013. Não houve necessidade de cálculo amostral por se tratar de uma pesquisa censitária. 
Foram excluídos os alunos do curso em tela que não estavam matriculados ou cursando a disciplina Práticas Integrativas em Saúde II no primeiro semestre de 2013 ou que estavam matriculados, mas faltaram ao primeiro dia letivo.

$\mathrm{O}$ projeto de pesquisa foi submetido à avaliação do Comitê de Ética em Pesquisa (CEP) do Centro Universitário Cesmac e em seguida aprovado com o número de protocolo $1487 / 2012$. A pesquisa foi conduzida com os padróes éticos exigidos.

A coleta de dados foi realizada, portanto, no primeiro dia letivo da disciplina Práticas Integrativas em Saúde II, em sala de aula. Antes, porém, foi feito um contato inicial com os professores e solicitada a sua autorização para realizar a coleta. $\mathrm{Na}$ sala de aula foram dadas explicaçóes sobre a pesquisa, seus objetivos e feito o convite aos alunos para participar. Todos os alunos presentes à aula, num total de 44, aceitaram participar, e após a leitura e assinatura do Termo de Consentimento Livre e Esclarecido (TCLE), o questionário foi aplicado.

$\mathrm{O}$ instrumento de coleta de dados foi um questionário de questóes fechadas, semiestruturado com dados e informaçóes que tiveram como objetivo: caracterizar o estudante quanto ao início do curso, idade, gênero e experiências anteriores na área de enfermagem; compreender as suas expectativas em relaçáo ao estágio, pacientes e docentes da disciplina; suas dificuldades e contribuiçóes para melhorar o seu desempenho na disciplina em foco e em Semiologia Aplicada à Enfermagem I e II.

A pesquisa tem como bases de dados a Biblioteca Virtual da Saúde (BVS) e a Scientific Eletronic Library Online (SciELO). A busca foi delimitada também pela língua, incluindo estudos apenas em português. As opções de Descritores em Ciência da Saúde (DeCS) para acessar as publicações foram utilizadas nas seguintes combinações: percepção; estágio clínico; enfermagem.

Após a coleta, os dados e informaçóes foram selecionados e tabulados em uma planilha eletrônica (Microsoft Office Excel, versão 2007) e analisados através do programa Biostat 5.0. A apresentação dos dados e informaçōes ocorreu por meio de tabelas com análise descritiva dos resultados encontrados.

\section{Resultados e discussão}

Participaram do estudo 44 alunos, dos quais 39 $(88,64 \%)$ eram do sexo feminino e $5(11,36 \%)$ do sexo masculino, com idade média de 22,47 anos $(\mathrm{DP}=3,97)$, prevalecendo $29(65,90 \%)$ participantes da pesquisa entre 20 e 29 anos. Esses resultados entram em consonância com outros estudos ${ }^{7-9}$, caracterizando a predominância de jovens do sexo feminino na graduação de enfermagem, presumindo, assim, inexperiência em novas vivências que podem advir no estágio hospitalar.

Em relação ao ingresso na faculdade, 35 (79,55\%) dos participantes da pesquisa ingressaram em 2011, o que demonstra que ainda não haviam passado pela disciplina Práticas Integrativas em Saúde II.

Importante destacar que 11 (25\%) dos estudantes possuem algum tipo de experiência na área de enfermagem hospitalar, sendo que $8(72,73 \%)$ frequentaram o curso técnico ou auxiliar de enfermagem e todos atuaram na profissão, tendo $5(62,50 \%)$ permanecido na área durante o período de 3 a 5 anos. Essa experiência revela maiores possibilidades de aprimoramento das técnicas, habilidades e conseguintemente maior segurança no ato de cuidar e, portanto, terão menos dificuldades de adaptação em relação aos que não trazem essa experiência. No entanto, apesar de possuírem experiência na área, esses estudantes podem apresentar dificuldades quanto à sistematização da assistência de enfermagem e ainda são mais exigidos em termos de habilidades técnicas pelos professores. Além disso, eles apresentam muitos vícios na realizaçáo dos procedimentos, mas são avaliados de acordo com os conhecimentos teóricos e práticos aprendidos na disciplina de Semiologia Aplicada à Enfermagem II. Vale ressaltar que a turma é caracterizada pela maioria de estudantes sem experiência na área de enfermagem hospitalar, representada por $33(75 \%)$ alunos, o que também foi observado em outra pesquisa, em que $49(94,23 \%)$ pessoas afirmaram não possuir nenhuma experiência 5 .

Ao avaliar se os alunos se sentiam preparados para iniciar o estágio hospitalar, foram encontrados resultados afirmativos de $36(81,82 \%)$ alunos. O estágio de um estudante no âmbito hospitalar constitui uma parte fundamental da sua formação e preparação para a entrada no mundo profissional. Ao afirmar que estão preparados, os estagiários asseguram experiências significativas e exemplificativas da realidade para promover as competências necessárias ao futuro profissional $^{10}$.

Em relação à segurança ao realizar as técnicas vistas na disciplina Semiologia Aplicada à Enfermagem II, 36 $(81,82 \%)$ assinalaram que se sentem seguros, demonstrando que a maioria sente-se apta para consolidar o ensino teórico, sendo o estágio o melhor ambiente para articular a teoria com a prática.

Analisando as expectativas em relação ao primeiro estágio hospitalar, constatou-se que a maior parte dos alunos - $29(65,91 \%)$ deles - refere como fator principal adquirir confiança, seguido das demais alternativas, conforme a Tabela 1. 
Tabela 1: Expectativa dos alunos em relação ao primeiro estágio hospitalar.

\begin{tabular}{|cccc}
\hline Categorias & $\begin{array}{c}\text { Assinalaram } \\
\mathbf{n}(\%)\end{array}$ & $\begin{array}{c}\text { Náo assinalaram } \\
\mathbf{n}(\%)\end{array}$ & $\begin{array}{c}\text { Total } \\
\mathbf{n}(\%)\end{array}$ \\
\hline $\begin{array}{c}\text { Conhecer as } \\
\text { técnicas }\end{array}$ & $18(40,91)$ & $26(59,09)$ & $44(100)$ \\
\hline $\begin{array}{c}\text { Adquirir } \\
\text { confiança }\end{array}$ & $29(65,91)$ & $15(34,09)$ & $44(100)$ \\
$\begin{array}{c}\text { Conhecer } \\
\text { relação }\end{array}$ & $20(45,45)$ & $24(54,55)$ & $44(100)$ \\
$\begin{array}{c}\text { profissional- } \\
\text {-paciente } \\
\text { Sem }\end{array}$ & $2(4,55)$ & $42(95,45)$ & $44(100)$ \\
\hline expectativa & & & \\
\hline
\end{tabular}

Fonte: Dados coletados pelos autores (2013-2014).

Os alunos demonstraram ter uma maior expectativa em adquirir confiança, pressupondo uma insegurança quanto à realidade hospitalar, o que também foi relatado por Pereira ${ }^{11}$. Ao se inserir no campo de estágio e executar seus conhecimentos teóricos na prática, o aluno torna-se autoconfiante com o decorrer do tempo ${ }^{10-12}$. Esse sentimento de segurança auxilia em seu desenvolvimento e consolida a sua interaçáo no campo.

A Tabela 2 mostra os fatores em que os discentes sentem mais dificuldades em relação ao estágio hospitalar. Dentre as dificuldades citadas pelos alunos, a falta de confiança/insegurança e ansiedade foram as mais frequentes, representando $20(45,45 \%)$ e $19(43,18 \%)$, respectivamente.

Tabela 2: Fatores em que os discentes sentem mais dificuldades em relação ao estágio hospitalar.

\begin{tabular}{|cccc} 
Categorias & $\begin{array}{c}\text { Assinalaram } \\
\mathbf{n}(\%)\end{array}$ & $\begin{array}{c}\text { Náo } \\
\text { assinalaram } \\
\mathbf{n}(\%)\end{array}$ & $\begin{array}{c}\text { Total } \\
\mathbf{n}(\%)\end{array}$ \\
\hline Conhecimento & $1(2,27)$ & $43(97,73)$ & $44(100)$ \\
Medo & $8(18,18)$ & $36(81,82)$ & $44(100)$ \\
\hline $\begin{array}{c}\text { Falta de confiança/ } \\
\text { Insegurança }\end{array}$ & $20(45,45)$ & $22(54,55)$ & $44(100)$ \\
\hline Ansiedade & $19(43,18)$ & $25(56,82)$ & $44(100)$ \\
\hline Sem expectativa & $6(13,64)$ & $38(86,36)$ & $44(100)$ \\
\hline
\end{tabular}

Fonte: Dados coletados pelos autores (2013-2014).

A inexperiência e a necessidade de enfrentar e vivenciar algo novo traduzem a insegurança, principalmente quando se depara com o primeiro contato real com o paciente, gerando um desequilíbrio emocional e induzindo a ansiedade, cujo grande motivo é o medo de errar, prejudicando o seu desempenho e alterando o aspecto emocional do aluno, e em consequência acometendo o paciente ${ }^{13}$. Porém, essa ansiedade estimula os estudantes à busca de conhecimento e de um melhor desempenho. Essa correlação entre a insegurança e a ansiedade também é observada por outros autores ${ }^{4,11,14}$.

Quanto às expectativas dos alunos de PIS II em relação ao professor durante o estágio hospitalar, 37 (84,09\%) dos discentes almejam que o educador se torne um transmissor de conhecimento, conforme mostra a Tabela 3.

Tabela 3: Expectativas dos alunos em relação ao professor durante ao estágio hospitalar.

\begin{tabular}{|cccc|}
\hline Categorias & $\begin{array}{c}\text { Assinalaram } \\
\mathbf{n}(\%)\end{array}$ & $\begin{array}{c}\text { Náo assinalaram } \\
\mathbf{n}(\%)\end{array}$ & $\begin{array}{c}\text { Total } \\
\mathbf{n}(\%)\end{array}$ \\
\hline $\begin{array}{c}\text { Transmissor de } \\
\text { confiança }\end{array}$ & $23(52,27)$ & $21(47,73)$ & $44(100)$ \\
$\begin{array}{c}\text { Calmo e } \\
\text { compreensivo }\end{array}$ & $16(36,36)$ & $28(63,64)$ & $44(100)$ \\
\hline $\begin{array}{c}\text { Transmissor de } \\
\text { conhecimento } \\
\text { Rígido e }\end{array}$ & $37(84,09)$ & $7(15,91)$ & $44(100)$ \\
$\begin{array}{c}\text { intolerante } \\
\text { Sem expectativa }\end{array}$ & $0(0)$ & $44(100)$ & $44(100)$ \\
\hline
\end{tabular}

Fonte: Dados coletados pelos autores (2013-2014).

O professor é a ponte entre o conhecimento e a práti$\mathrm{ca}$, devendo transformar o aprendizado em uma experiência prazerosa e desafiadora. Outros autores contrariam a ideia de o professor ser um transmissor de conhecimento, afirmando que ele induz o conhecimento aos alunos ${ }^{15,16}$.

Hoje, o professor não assume somente uma postura de transmissor de conhecimento, mas vem sofrendo transformaçóes motivadas pelas necessidades que surgem em sala de aula, fazendo que seja um "gerenciador da informação, reflexivo um facilitador da aprendizagem do aluno e da construção dos sentidos"17. Essa mudança fez que o aluno também alterasse sua postura, tornando-se mais participativo e questionador ${ }^{17}$.

Um professor com uma postura rígida, por seu nível de exigência, gera tensão e estresse no estudante, atrapalhando seu desenvolvimento. No presente estudo, nenhum aluno espera que o professor seja rígido e intolerante.

A Tabela 4 mostra as expectativas dos alunos em relaçáo ao paciente e à equipe do hospital. As mais assinaladas foram "bom relacionamento" e "aprender a trabalhar em equipe", ambas representando $28(63,64 \%)$ dos entrevistados.

Tabela 4: Expectativas dos discentes frente ao paciente e as outras pessoas do hospital.

\begin{tabular}{cccc} 
Categorias & $\begin{array}{c}\text { Assinalaram } \\
\mathbf{n}(\%)\end{array}$ & $\begin{array}{c}\text { Náo assinalaram } \\
\mathbf{n}(\%)\end{array}$ & $\begin{array}{c}\text { Total } \\
\mathbf{n}(\%)\end{array}$ \\
\hline Criar vínculos & $6(13,64)$ & $38(86,36)$ & $44(100)$ \\
Bom relacionamento & $28(63,64)$ & $16(36,36)$ & $44(100)$ \\
Aprender a trabalhar & $28(63,64)$ & $16(36,36)$ & $44(100)$ \\
em equipe & $3(6,82)$ & $41(93,18)$ & $44(100)$ \\
\hline Sem expectativa & 30
\end{tabular}

Fonte: Dados coletados pelos autores (2013-2014). 
No hospital, por ser um ambiente complexo de ensino-aprendizagem, é esperado que os alunos tenham um bom relacionamento com os profissionais e pacientes para que possam aprender a trabalhar em equipe. É necessária a intervenção do professor, preparando a equipe de enfermagem quanto ao bom relacionamento, compreensão e paciência em relação aos estagiários, devendo orientá-los que essa fase é a primeira inserção do aluno no ambiente hospitalar, e que o tempo de execução das tarefas do estagiário em aprendizagem não é o mesmo que o do profissional já experiente. Dessa forma, esse processo comunicativo beneficiaria a qualidade da assistência ao paciente.

Quanto aos fatores que mais afligem os discentes na relação terapêutica com o paciente, a empatia representou $18(40,91 \%)$ respostas, sendo considerada como o fator mais importante. A confiança apareceu em segundo lugar, tendo sido assinalada por $15(34,09 \%)$ alunos (Tabela 5).

Tabela 5: Fatores que mais afligem os discentes na relação terapêutica com o paciente.

\begin{tabular}{|cccc} 
Categorias & $\begin{array}{c}\text { Assinalaram } \\
\mathbf{n ( \% )}\end{array}$ & $\begin{array}{c}\text { Náo } \\
\text { assinalaram } \\
\mathbf{n}(\%)\end{array}$ & $\begin{array}{c}\text { Total } \\
\mathbf{n}(\%)\end{array}$ \\
\hline Empatia & $18(40,91)$ & $26(59,09)$ & $44(100)$ \\
\hline Respeito & $8(18,18)$ & $36(81,82)$ & $44(100)$ \\
\hline Confiança & $15(34,09)$ & $29(65,91)$ & $44(100)$ \\
\hline Outros & $7(15,91)$ & $37(84,09)$ & $44(100)$ \\
\hline Não responderam & $1(2,27)$ & $43(97,73)$ & $44(100)$ \\
\hline
\end{tabular}

Fonte: Dados coletados pelos autores (2013-2014).

Esse resultado demonstra que os estudantes têm dificuldade de se colocar no lugar do outro e tentar ver o mundo como a outra pessoa vê, sem perder a identidade. No entanto, sentir a experiência do outro, tal como ele a percebe, pode favorecer a relação profissional com o paciente e, consequentemente, melhorar a qualidade da assistência prestada.

Acredita-se que a empatia é a melhor forma de se aproximar do paciente, pois exige um relacionamento estreito. Através da comunicação é possível compreender a experiência do outro, interferindo na relaçáo terapêutica.

Para ter empatia é necessário ter confiança mútua, e apenas no convívio o discente e o paciente podem estabelecer um vínculo, tão enfocado como primordial para a humanização da assistência. Dessa forma, os fatores "empatia" e "confiança" podem ajudar no tratamento do paciente ${ }^{18}$.

Ao investigar como os discentes se sentiam como um quase estagiário no âmbito hospitalar, foi constatado que $27(61,36 \%)$ alunos estavam ansiosos, como pode ser visto na Tabela 6 .
Tabela 6: Resultado de como os discentes se sentem como um quase estagiário no âmbito hospitalar.

\begin{tabular}{cccc} 
Categorias & $\begin{array}{c}\text { Assinalaram } \\
\mathbf{n}(\%)\end{array}$ & $\begin{array}{c}\text { Náo } \\
\text { assinalaram } \\
\mathbf{n}(\%)\end{array}$ & $\begin{array}{c}\text { Total } \\
\mathbf{n}(\%)\end{array}$ \\
\hline Calmo/Tranquilo & $12(27,27)$ & $32(72,73)$ & $44(100)$ \\
\hline Eufórico & $2(4,55)$ & $42(95,45)$ & $44(100)$ \\
\hline Empolgado & $12(27,27)$ & $32(72,73)$ & $44(100)$ \\
\hline Ansioso & $27(61,36)$ & $17(38,64)$ & $44(100)$ \\
\hline Curioso & $22(50)$ & $22(50)$ & $44(100)$ \\
\hline Outro & $3(6,82)$ & $41(93,18)$ & $44(100)$ \\
\hline
\end{tabular}

Fonte: Dados coletados pelos autores (2013-2014).

A ansiedade é retomada novamente pelos alunos em um novo questionamento, pois quando se deparam com o novo, vem o sentimento de ansiedade, de "como vai ser?", "como irei me comportar?", "irei realizar os procedimentos corretamente?", "como será o relacionamento com a equipe e os pacientes?", sendo esse sentimento motivado pela falta de experiência e de convívio no âmbito hospitalar.

O sentimento de ansiedade, de certa forma, é considerado normal e esperado entre os estudantes, porém, quando exagerado, influencia de modo negativo no aprendizado e no desenvolvimento do aluno. Sendo assim, é imprescindível o acompanhamento desses alunos pelo docente, assistindo o seu desenvolver no estágio e minimizando com a vivência em campo esse sentimento.

Quanto à avaliaçáo dos discentes acerca do ensino da disciplina Semiologia Aplicada à Enfermagem II e sua relação com a preparação dos alunos para PIS II, $39(88,64 \%)$ dos alunos alegaram que a disciplina dá o suporte adequado para a disciplina PIS II; entretanto, consideram que para uma melhor adaptaçáo do aluno ao ambiente hospitalar, as práticas realizadas durante PIS II deveriam ser incluídas na disciplina Semiologia Aplicada à Enfermagem, para que não houvesse um distanciamento entre teoria e prática. Assim, 36 (81,82\%) estudantes acreditam que isso diminuiria a ansiedade $\mathrm{e}$ facilitaria a inserção do aluno no ambiente hospitalar.

Portanto, a associaçáo da teoria e prática em um mesmo momento auxiliaria na inserçáo do discente no seu primeiro estágio hospitalar, pois não seria o seu primeiro contato com o paciente, amenizando sentimentos e dificuldades.

\section{Conclusão}

É importante resgatar que a mola propulsora para a realizaçáo do presente estudo foi a necessidade de conhecer as expectativas dos alunos em relação ao seu 
primeiro estágio no ambiente hospitalar, aprofundando o olhar e descobrindo os sentimentos e dificuldades encontradas nessa etapa, já que a entrada repentina em um ambiente novo e desconhecido provoca angústia, dificuldades e incertezas.

Em conjunto, os achados deste estudo mostraram que a maioria dos discentes entrevistados relatou sentir ansiedade e insegurança em relação ao primeiro estágio no âmbito hospitalar. As suas principais expectativas foram adquirir confiança, aprender a trabalhar em equipe e ter bom relacionamento com os pacientes e a equipe do hospital. Entre as suas maiores afliçóes se encontra a dificuldade de sentir empatia em relação ao paciente a quem irá assistir enquanto estagiário. Para superar as dificuldades e expectativas citadas, o papel do docente preceptor é fundamental, devendo conduzir o estágio de forma calma, sendo compreensivo, transmitindo confiança ao aluno e sendo um ótimo transmissor de conhecimentos.

A hipótese enunciada para o presente estudo não foi confirmada, pois em vez de $90 \%$ de inseguros foi encontrado um percentual de $45,45 \%$. Entretanto, os autores concordam que esse percentual é alto e que pode ter reflexos negativos no processo ensino-aprendizagem desses alunos. Há, portanto, a necessidade de intervençóes por parte dos docentes com o intuito de minimizar esses problemas e, consequentemente, favorecer o desempenho dos alunos, além de melhorar a associaçáo entre teoria e prática, envolvendo as disciplinas Semiologia Aplicada à Enfermagem e Práticas Integrativas em Saúde II.

\section{Referências}

1. Lima MJ. O que é enfermagem. São Paulo: Brasiliense; 2005.

2. Souza ML, Sartor VVB, Padilha MICS, Prado ML. O cuidado de enfermagem: uma aproximação teórica. Texto Contexto Enferm. 2005; 14:266-70.

3. Valsecchi EASS, Nogueira MS. Comunicaçâo professor-aluno: aspectos relacionados ao estágio supervisionado. Ciência, Cuidado e Saúde. 2002;1(1):137-43.

4. Bosquetti LS, Braga EM. Reaçôes comunicativas dos alunos de enfermagem frente ao primeiro estágio curricular. Rev Esc Enferm USP. 2008;42(4):690-6.

5. Lúcio FD, Peres GRP, Ramin CSA, Souza DSB. Os sentimentos dos alunos do curso de graduação em enfermagem frente ao primeiro estágio. Brasília (DF): ABEn; 2005. [Acesso em
15 maio 2012]. Disponível em: http://www.bstorm.com. br/enfermagem/index-p2.php?cod=61668\&popup $=1$

6. Andrade MN, Andrade FL. Estágio curricular: avaliação de experiência. Rev Bras Enferm. 1989;4:27-41.

7. Karino ME, Guariente MHDM. O aprendizado no primeiro estágio de enfermagem: a visão dos alunos. Arq Ciênc Saúde Unipar. 2001;5(1):33-9.

8. Spíndola T, Martins ERC, Francisco MTR. Enfermagem como opção: perfil de graduandos de duas instituiçóes de ensino. Rev Bras Enferm. 2008;61(2):164-9.

9. Donati L, Alves MJ, Camelo SHH. O perfil do estudante ingressante no curso de graduação em enfermagem de uma faculdade privada. Rev Enferm UERJ. 2010;18(3):446-50.

10. Macedo AP. Os estágios dos estudantes de enfermagem enquanto actividade formativa em contexto hospitalar. Actas dos ateliers do V Congresso Português de Sociologia. Braga: Ed. Universidade do Minho; 2004.

11. Pereira CD. Expectativas dos acadêmicos de enfermagem relacionadas à primeira disciplina prática do curso de graduação em enfermagem [Mamografia]. Novo Hamburgo: Centro Universitário Feevale; 2008.

12. Carvalho et al. Administração de medicamentos: a vivência dos alunos em seu primeiro estágio. Acta Scientiarum. Health Sciences. 2003;25(1):13-8.

13. Carvalho R, Farah OGD, Galdeano LE. Níveis de ansiedade de alunos de graduação em enfermagem frente à primeira instrumentação cirúrgica. Rev Lat Am Enfermagem. 2004;12(6):918-23.

14. Higarashi IH, Nale N. O estágio supervisionado de enfermagem em hospitais como espaço de ensino-aprendizagem: uma avaliação. Ciência, Cuidado e Saúde. 2006;5:65-70.

15. De Domenico EBL, Ide CAC. Referências para o ensino de competências na enfermagem. Rev Bras Enferm. 2005;58(4):453-7.

16. Paranhos VD, Mendes MMR. Currículo por competência e metodologia ativa: percepção de estudantes de enfermagem. Rev Lat Am Enfermagem. 2010;18(1):[07 telas].

17. Lucchese R, Barros S. Pedagogia das competências um referencial para a transição paradigmática no ensino de enfermagem: uma revisão da literatura. Acta Paul Enferm. 2006;19(1):92-9.

18. Casate JC, Corrêa AK. Vivências de alunos de enfermagem em estágio hospitalar: subsídios para refletir sobre a humanização em saúde. Rev Esc Enferm USP. 2006;40(3):321-8.

\section{Como citar este artigo:}

Lima JA, Carrilho AB, Santos LD, Lima UTS. Expectativas do estágio hospitalar para estudantes de enfermagem. Rev. Aten. Saúde. 2016;14(48):5-10. 